\title{
Ndola Demonstration Project: A midterm analysis of lessons learned
}

Horizons Program

Follow this and additional works at: https://knowledgecommons.popcouncil.org/departments_sbsr-hiv

Part of the Family, Life Course, and Society Commons, International Public Health Commons, and the Maternal and Child Health Commons

How does access to this work benefit you? Let us know!

\section{Recommended Citation}

Horizons Program. 2002. "Ndola Demonstration Project: A midterm analysis of lessons learned," Horizons Report. Nairobi: Population Council. 


\section{Ndola Demonstration Project: A Midterm Analysis of Lessons Learned}

\section{Horizons $\boldsymbol{N}$}




\title{
Ndola Demonstration Project: A Midterm Analysis of Lessons Learned
}

\author{
Hope Humana \\ LI NKAGES \\ National Food and Nutrition Commission \\ Ndola District Health Management Team \\ Horizons Program \\ Zambia Integrated Health Project
}
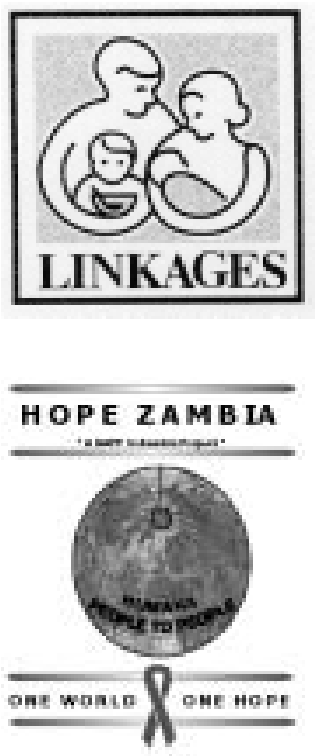
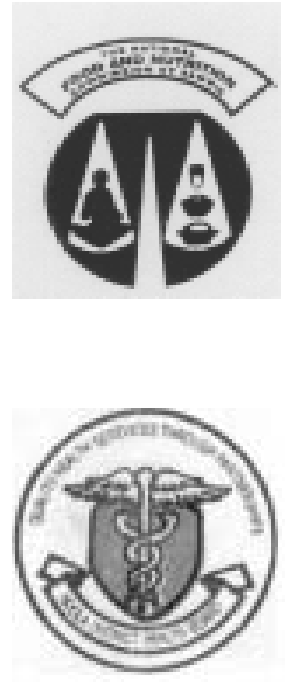

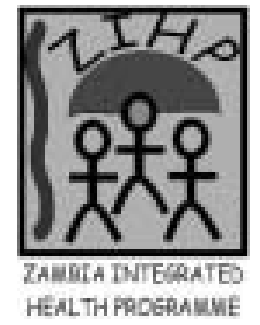

${ }^{\text {Hrizons }}$ 
This material may be quoted or reproduced without charge for noncommercial purposes only; however, please acknowledge source and send a copy of reproduced material to the LINKAGES Project, Horizons, and the Ndola District Health Management Team.

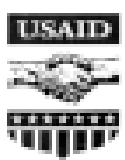

This study was supported by the Horizons Program, which is implemented by the Population Council in collaboration with the International Center for Research on Women, International HIV/AIDS Alliance, Program for Appropriate Technology in Health, Tulane University, Family Health International, and Johns Hopkins University. Horizons is funded by the U.S. Agency for International Development, under the terms of HRN-A-00-97-00012-00. The opinions expressed herein are those of the authors and do not necessary reflect the views of the U.S. Agency for International Development.

Published in November 2002.

Population Council

The Population Council is an international, nonprofit, nongovernmental institution that seeks to improve the wellbeing and reproductive health of current and future generations around the world and to help achieve a humane, equitable and sustainable balance between people and resources. The Council conducts biomedical, social science and public health research and helps build research capacities in developing countries. Established in 1952, the Council is governed by an international board of trustees. Its New York headquarters supports a global network of regional and country offices.

Copyright $@ 2002$ The Population Council Inc.

LINKAGES project of the Academy for Educational Development 3039 Makhishi Road, Fair View

P.O. Box 32242

Lusaka, Zambia

tel: +2601234 11/2

linkages@link.org.zm

www.linkagesproject.org
Horizons Program Population Council

P.O. Box 17643

Nairobi, Kenya

tel: +2542713480

pcnairobi@popcouncil.org

www.popcouncil.org/horizons

Correct citation:

Horizons Program. 2002. Ndola Demonstration Project: a midterm analysis of lessons learned. Nairobi: Population Council. 


\section{Acknowledgments}

The research component of the Ndola Demonstration Project (NDP) is conducted by Horizons, a USAID-funded global HIV/AIDS operations research project implemented by the Population Council. Horizons' principal investigator for the NDP is Sam Kalibala. Other Horizons team members that have contributed to this report (listed alphabetically) include Margaret Dadian, program associate; Julie Denison, program fellow; Scott Geibel, data analyst; Winnie Lubasi, administrative assistant; Norah Omenda, administrative assistant; Naomi Rutenberg, director of research; and Katie Schenk, program associate.

The NDP is implemented by the following partners, who have all contributed to the study:

LINKAGES provided leadership, guidance, and technical assistance in conceptualizing and developing the research proposal, including the data collection tools. LINKAGES' principal investigator for the NDP is Nomajoni Ntombela, LINKAGES/Zambia resident adviser. Other LINKAGES team members that contributed to this report include Jean Baker, LINKAGES project director; Melissa Barrett, senior monitoring and evaluation associate; Henry Chiyota, program associate; Nadra Franklin, monitoring and evaluation manager; Mary Kroeger, maternal and child health coordinator; Carolyn Kruger, country programs technical manager; Maureen Muzumara, training officer; Tina Nyirenda, training officer; and Jean Tshiula, technical program officer.

The National Food and Nutrition Commission (NFNC) provided overall national input into the study as well as technical assistance on nutrition issues in developing data collection tools. The following NFNC staff also directly participated in all aspects of the study: Mwate Chintu, national coordinator for the Infant Feeding Program; Priscilla Likwasi, acting executive director; Ward Siamusante, nutritionist; and Ruth Siyandi, nutritionist (seconded to the program).

Ndola District Health Management Team (DHMT) was the main implementer of NDP services and provided overall guidance in the day-to-day management of research activities. DHMT's principal investigator for the NDP is Ernest Muyunda. Other DHMT staff who participated in the NDP include Mwila Lembalemba, manager of planning; Esther Sakala, manager; Ronah Maambo, AIDS/HIV/STD coordinator; Lynette Maambo, community partnerships coordinator; Ricky Ndhlovu, information officer; Angel Sondashi, laboratory technician; and Feiby Moonga, laboratory technician.

The sisters in charge of the clinics in the study area are Kabushi: Beauty Maluti and Godreen Kapotwe; Kaloko: Apronia Musopelo; Lubuto: Anne Banda; Masala: Mary Sichula; Mushili: Egina Phiri; and Twapia: Agnes Mwafulilwa.

The Hope Humana team provided logistics management and participated in various aspects of the study. The team included Millie Bwalya Chikolwa, administrative support; Tresford Chomba, laboratory technician; Wendy Dunnett-Dagg, assistant project manager; Jane Jensen, director; 
Nila Kaetano, counselor; Chad Kalobwe, community mobilizer; Esnelly Kasongo, counselor; and the late Poso Ngalande, clinical program manager.

The Zambia Integrated Health Project (ZIHP) team was a partner throughout various stages of the NDP, from conceptualizing the study to implementing it. Team members included Andrew Mlewa, NGO support coordinator; Bruce Mukwatu, interventions coordinator; Simon Mutonyi, NGO support coordinator; Nosa Orabaton; Elizabeth Serlemitsos, chief of party; Grace Sinyangwe, communication coordinator; Rose Zambezi, community partnerships specialist.

The NDP Operations Research team under DHMT, supported by Horizons and based at Hope Humana, was responsible for the day-to-day operation of the study. This team consisted of: the late Hilda Kaunda, study coordinator; Queen Moyowanyambe, research assistant; Stephanie Mpabalwani, assistant study coordinator; Mary Mufaya, research assistant; Elizabeth Nonde, research assistant; Jennifer Ntinda, study secretary and qualitative data entry; Esther Sakala, study coordinator; and Kedrick Sikaona and Lenganje Sikaona, quantitative data entry.

The following consultants provided technical assistance to the operations research team on behalf of Horizons: Fred Kaona; Rosemary Musonda, Tropical Diseases Research Centre; David Mwandu, Mwengu Social and Health Research; Mary Tuba Siajunza, Mwengu Social and Health Research; and Helen van Houten.

Research assistants during the baseline and midterm surveys are listed in the appendix. 


\section{Table of Contents}

\section{Acronyms and Abbreviations}

Executive Summary 1

Introduction 4

Ndola Demonstration Project 5

$\begin{array}{ll}\text { NDP sites } & 8\end{array}$

Study Methods 9

Study design $\quad 9$

$\begin{array}{lr}\text { Data collection } & 9\end{array}$

$\begin{array}{lr}\text { Data entry and analysis } & 12\end{array}$

Results $\quad 13$

$\begin{array}{ll}\text { Profile of respondents } & 13\end{array}$

$\begin{array}{ll}\text { MTCT knowledge } & 16\end{array}$

Voluntary counseling and testing $\quad 20$

$\begin{array}{ll}\text { Antenatal and postnatal care } & 22\end{array}$

$\begin{array}{ll}\text { Infant feeding } & 24\end{array}$

$\begin{array}{ll}\text { HIV prevention and care issues } & 28\end{array}$

Discussion and Recommendations $\quad 30$

Study limitations $\quad 30$

MTCT knowledge improved but still incomplete 30

$\begin{array}{ll}\text { Breastfeeding practices improved } & 30\end{array}$ 
Partner communication and sexual risk reduction need further emphasis in the community

VCT uptake and disclosure remain low despite service improvements

Routine ANC services also need additional resources

References

\section{Appendixes:}

A. Service Statistics (July 2001) 35

B. Referrals Data 36

C. Ndola Demonstration Project Staff 37 


\section{Abbreviations and Acronyms}

\begin{tabular}{|c|c|}
\hline $\mathrm{ADH}$ & Arthur Davison Hospital \\
\hline AIDS & acquired immune deficiency syndrome \\
\hline ANC & antenatal care \\
\hline ARV & antiretroviral \\
\hline $\mathrm{CBO}$ & community-based organization \\
\hline $\mathrm{CHW}$ & community health worker \\
\hline DHMT & District Health Management Team \\
\hline DHS & Demographic and Health Survey \\
\hline EBR & exclusive breastfeeding rate \\
\hline FP & family planning \\
\hline $\mathrm{Hb}$ & hemoglobin \\
\hline HIV & human immunodeficiency virus \\
\hline IF & infant feeding \\
\hline IFC & infant feeding counseling \\
\hline KAP & knowledge, attitudes, and practices \\
\hline $\mathrm{MCH}$ & maternal and child health \\
\hline $\mathrm{MOH}$ & Ministry of Health \\
\hline MTCT & mother-to-child transmission \\
\hline $\mathrm{NCH}$ & Ndola Central Hospital \\
\hline NDP & Ndola Demonstration Project \\
\hline NFNC & National Food and Nutrition Commission \\
\hline NGO & nongovernmental organization \\
\hline PLHA & people/person living with HIV/AIDS \\
\hline PMCT & prevention of mother-to-child transmission \\
\hline PNC & postnatal care \\
\hline STD & sexually transmitted disease \\
\hline TDRC & Tropical Disease Research Centre \\
\hline UN & United Nations \\
\hline USAID & United States Agency for International Development \\
\hline VCT & voluntary counseling and testing \\
\hline WHO & World Health Organisation \\
\hline ZIHP & Zambia Integrated Health Program \\
\hline
\end{tabular}


NDP: Midterm Analysis

\section{Executive Summary}

This report summarizes baseline and midterm findings of an intervention pilot study conducted by Horizons, LINKAGES, National Food and Nutrition Commission, District Health Management Team, Hope Humana, and the Zambia Integrated Health Program in Ndola District, Zambia. The aim of the research is to investigate how integrating services for the prevention of mother-to-child transmission (PMCT) of HIV into low-resource maternal and child health (MCH) and antenatal care (ANC) settings influences women's ability to make and implement informed decisions about HIV. The intervention strengthened routine services and introduced HIV voluntary counseling and testing (VCT) and PMCT counseling and services into the MCH/ANC setting. Exclusive breastfeeding was promoted for all mothers with infants below 6 months old.

\section{Key Findings}

\section{Community knowledge of mother-to-child transmission (MTCT) improved but remains incomplete.}

The study found that the clinic-based intervention had diffused to reach the community at large by midterm; although awareness of MTCT modes improved among community members, knowledge of prevention methods remains incomplete. Knowledge of exclusive breastfeeding as a means to reduce MTCT increased significantly across all respondents but remained low, which suggests a need for more education on the role of exclusive breastfeeding in PMCT.

\section{Breastfeeding practices improved.}

Mothers increasingly adopted the safer practice of exclusive breastfeeding, and the riskier practice of mixed feeding declined. The exclusive breastfeeding rate (EBR) among mothers of infants under six months attending maternal and child health clinics who did not know their HIV status rose from 71 percent at baseline to 85 percent at midterm. This increase implies that good breastfeeding practices are not being eroded, even as the Ndola Demonstration Project (NDP) increases women's knowledge that HIV can be passed from a mother to her child through breastfeeding. At baseline, the community EBR was surprisingly high at 56 percent and had reached 76 percent by midterm. The potentially confounding role of previous breastfeeding initiatives in the area is unknown, but steps were taken at midterm to confirm and validate data collection methods, including strengthening sampling procedures.

NDP advice on beginning complementary feeding at 6 months appears to be successfully reaching mothers at clinics and is reflected in reported improved complementary feeding practices among clinic and community mothers. However, almost all mothers of infants up to 12 months old were currently breastfeeding when interviewed, indicating that HIV status awareness appears not to have 


\section{Herizons}

affected the practice of continuing to give breast milk beyond 6 months. Among the reasons for this are economic considerations and a desire to avoid the stigma associated with not breastfeeding.

\section{Sexual risk reduction and communication need further emphasis in the community.}

Among all community mothers, condom use at last sex with regular partners was low and remained stable between the surveys at approximately 13 percent. Data from the community surveys suggest that while women are reducing their number of sexual partners, no significant change was observed among men.

HIV risk reduction communication remains limited. Little change was observed among community mothers reporting that they had ever discussed HIV risks with anyone, including specific discussions with a partner.

\section{VCT uptake increased but remains low.}

Community awareness of the availability of confidential free VCT services increased significantly, from 45 percent at baseline to 75 percent at midterm. Meanwhile, service uptake increased but remained low, suggesting that although community members are aware of the service, they are choosing not to use it. The community survey revealed that VCT is increasingly perceived as a source of stress, rather than a way to reduce worries.

\section{Routine ANC services also need additional resources.}

The intervention aimed to strengthen care during pregnancy, delivery, and the postnatal period by improving clinic infrastructure, providing supplies, and building health workers' numbers and capacity. However, survey data and clinic observations revealed that logistical obstacles hampered some of these goals.

\section{Care and support links remain poor.}

Community links are essential to promoting services and providing follow-up support for mothers after leaving the clinic. Observations indicate that referrals remain limited to major hospitals for medical indications only, and not to NGOs to meet care and support needs. Improved collaboration among clinics and NGOs would help provide continuity of care, ongoing information, and support structures for people/person living with HIV/AIDS (PLHA). 


\section{Conclusions and Recommendations}

Increasing women's MTCT knowledge did not appear to erode good breastfeeding practices. Despite acquiring knowledge that HIV may be transmitted through breast milk, mothers' capacity to evaluate relative risks and benefits increased, and they made infant feeding decisions favoring their infant's health.

Women remain at risk of HIV infection during the perinatal period due to their partners' behavior. Research should explore innovative ways to reach men, including community education campaigns and couple counseling, to educate about risk reduction and communication.

Although the logistical requirements of setting up VCT services were met, uptake remained low, demonstrating that supply-side obstacles were successfully overcome but demand-side factors remain to be addressed. Service providers should focus on increasing demand by drawing attention to the benefits of testing and examining whether further service improvements are required to reduce disincentives.

The erratic availability of basic supplies hampered provision of a comprehensive $\mathrm{MCH}$ package, while new inputs were limited to enhanced program components. In addition to providing enhanced services for selected elements, MTCT risk-reduction programs must strengthen routine care as an integral component. Health workers and clinic infrastructure require ongoing investment to provide communities with routine and enhanced services.

Without a comparison area and without tools to measure intervention coverage the NDP findings cannot be attributed to the intervention alone. However, the study demonstrated encouraging results that merit further investigation. 


\section{H ${ }^{\text {rizons }}$}

\section{Introduction}

The prevention of mother-to-child HIV transmission has emerged as a critical issue in many parts of the world, particularly sub-Saharan Africa. The World Health Organization (WHO) and other UN agencies have proposed the following three-pronged approach for the PMCT:

- Primary prevention of HIV among young women.

- Prevention of unintended pregnancy among HIV-infected women.

- Interventions to reduce MTCT from HIV infected pregnant and lactating women.

In addition, they have proposed a fourth prong, the care and support of women, children, and families infected and affected by HIV/AIDS, which has gained wide acceptance as an important component of MTCT interventions (de Zoysa et al. 2002).

For women to make informed decisions about reducing their risks and seek care, they must know their HIV status. Making VCT services and follow-up care and support available in clinics and communities therefore becomes an urgent priority. United Nations (UN) guidelines (UNAIDS 1998) recommend that all pregnant women receive voluntary counseling and testing for HIV. This guidance also encourages service providers to counsel HIV-positive mothers about infant feeding options and provide support to mothers in their chosen infant feeding method. Counseling should also include the provision of information about protection from further risks of infection, minimizing the risk of HIV transmission to the pregnant woman's partner(s) and children, and how to avoid further pregnancies if desired.

Of particular concern with regard to the prevention of MTCT is the fact that HIV can be transmitted through breastfeeding. It has been estimated that as many as 14 percent of infants born to HIV-positive women contract the virus through breastfeeding (LINKAGES 2001).

Unfortunately, refraining from breastfeeding may increase the risks of infant mortality by a factor of three to five in many areas with high HIV prevalence and may also be associated with the stigma of suspected HIV-positive status (LINKAGES 2001). In areas of high HIV prevalence, mothers must evaluate the relative risks and benefits of breastfeeding and formula feeding regimes when deciding how to feed their infants, whether or not they know their own HIV status.

The ANC clinic is an obvious setting to introduce a package of services to prevent MTCT, including infant feeding counseling (IFC), because of its use by women of reproductive age who may not otherwise have access to health services, at a time when they may be especially receptive to health information. However, introducing new services changes places additional demands on clinics, such as training staff and improving clinic infrastructure to ensure privacy and confidentiality.

In 1998, the Central Board of Health, the Ministry of Health (MOH), the National Food and Nutrition Commission (NFNC), LINKAGES, Zambia Integrated Health Package (ZIHP), Hope Humana, and Horizons, with the support of USAID, sought an opportunity to pilot the introduction of IFC as a PMCT intervention at ANC sites, at a time when antiretrovirals (ARVs) were largely 
unavailable. Ndola District was selected as a potential demonstration site because of its strong community mobilization efforts against HIV/AIDS, including a multisectoral District HIV/AIDS Task Force.

\section{Ndola Demonstration Project}

In collaboration with the partners listed above, the Ndola District Health Management Team (DHMT) developed the Ndola Demonstration Project (NDP) to test the operational feasibility of an integrated MTCT risk-reduction approach linked to ANC. The partners are now working together to evaluate the feasibility, acceptability, and implications of improving IFC and introducing VCT into a low-resource ANC/MCH clinic setting, where women do not have access to short-course ARVs such as nevirapine or AZT to reduce vertical transmission.

The main research question of this study is:

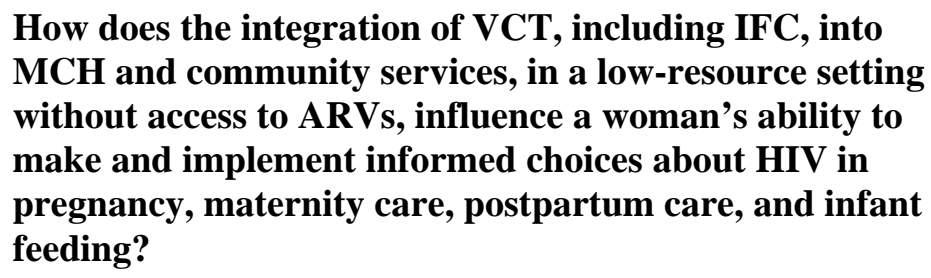

Specifically, the study aims to:

- Explore the feasibility of integrating IFC and VCT into enhanced MCH care services and a community-based network.

- Examine the effect of these interventions on the mothers' knowledge of MTCT, uptake of VCT, infant-feeding practices, and sexual behavior.

\section{Intervention package}

Prior to this intervention study, the LINKAGES and SARA projects conducted formative research during November-December 1998 to examine current infant feeding practices, identify appropriate replacement infant feeding methods, and determine the feasibility and acceptability of counseling women about these options (NFNC 1999). In April 1999, Horizons and other NDP partners conducted an assessment of community resources and capacity (Horizons 2000).

The formative research findings were used to design the NDP intervention package, which introduced the following initiatives through a strengthened essential ANC care program:

- Counseling on safe and feasible infant feeding options based on principles of informed choice (see below). 


\section{Hgrizons}

- Promoting exclusive breastfeeding for women who are HIV-negative or whose status is unknown.

- Introducing VCT for HIV in MCH and community services.

- Using optimal obstetric procedures during labor and delivery.

- Intensifying community involvement, including the promotion of couple counseling.

\section{Infant feeding counseling}

The most innovative aspect of the NDP is the placement of IFC as the centerpiece of the PMCT intervention. IFC is provided to women at various stages throughout the health care system. Infant feeding is among the ANC topics routinely covered by group talks given to mothers in the ANC waiting hall. Infant feeding is also discussed as part of pre- and post-test counseling for mothers choosing to receive VCT (see below). After delivery, mothers receive further infant feeding support at the time of discharge from the health center, at growth monitoring visits at the clinic, and at outreach posts. Systems of routine data collection have been established to record at which, if any, of these opportunities women have been counseled on infant feeding.

Women choosing to receive VCT first attend a confidential pre-testing counseling session with a certified counselor. If a woman decides to go ahead with the HIV test, her blood sample is collected on-site and sent to the laboratory for testing. A counselor confidentially discloses her test results when she returns after one week.

The content of the infant feeding counseling depends on whether or not the woman decides to go ahead with testing and the results she receives:

- A woman receiving a negative HIV test result is advised by the counselor to exclusively breastfeed her infant, in order to ensure that her child receives the full nutritional benefit of breast milk.

- A woman receiving a positive HIV test result is provided with information on the different infant feeding methods available to her, and the counselor guides her through the way in which these options might be influenced by socioeconomic and household factors.

- A woman choosing not to be tested for HIV receives exactly the same advice as if she had tested negative: exclusive breastfeeding.

\section{Program inputs}

To operationalize the intervention package, the program required human resources (staff and training) and physical resources. 
Human resources: A nursing sister in charge, a clinical officer, doctors visiting once a month, one or two registered midwives, and a number of enrolled midwives and enrolled nurses staff each of the six clinics. NDP health workers are DHMT employees, supervised by DHMT. The LINKAGES project supports a staff of three people to provide coordination, mentoring and support.

By August 2001, 99 project health workers and their supervisors from several institutions in the network (including DHMT) had attended a two-week training course covering HIV epidemiology, IFC, lactation management, the essential ANC package, risk-reduction strategies for the prevention of MTCT during labor and delivery, postnatal care, maternal health, and VCT. In addition, 104 community health workers, including neighborhood health committee (NHC) members, mother support group members, traditional birth attendants, growth monitors, and promoters had been trained in a modified course. Forty-seven clinic health workers and 25 community health workers completed additional counseling training for VCT providers. Most of this training took place before the midterm data collection.

DHMT managers, who oversee all NDP service provision, supervise clinic staff with technical assistance from the LINKAGES project staff. Hope Humana provided two counselors, alternating weekly, and a laboratory technician to provide the initial VCT services and mentor newly trained clinic staff.

Physical resources: NDP has enlarged the Lubuto Clinic to provide more ANC waiting room, counseling rooms, and a new laboratory.

With support from LINKAGES, NDP has purchased microscopes, hemoglobin testing equipment, refrigerators, and a centrifuge. The National VCT Service operated by the MOH provided HIV test kits and supplies including gloves and pipettes. However, the NDP has experienced supply problems with essential drugs and reagents for hemoglobin and syphilis testing. 


\section{${ }^{\mathrm{H}} \mathrm{K}^{\text {rizons }}$}

\section{NDP Sites}

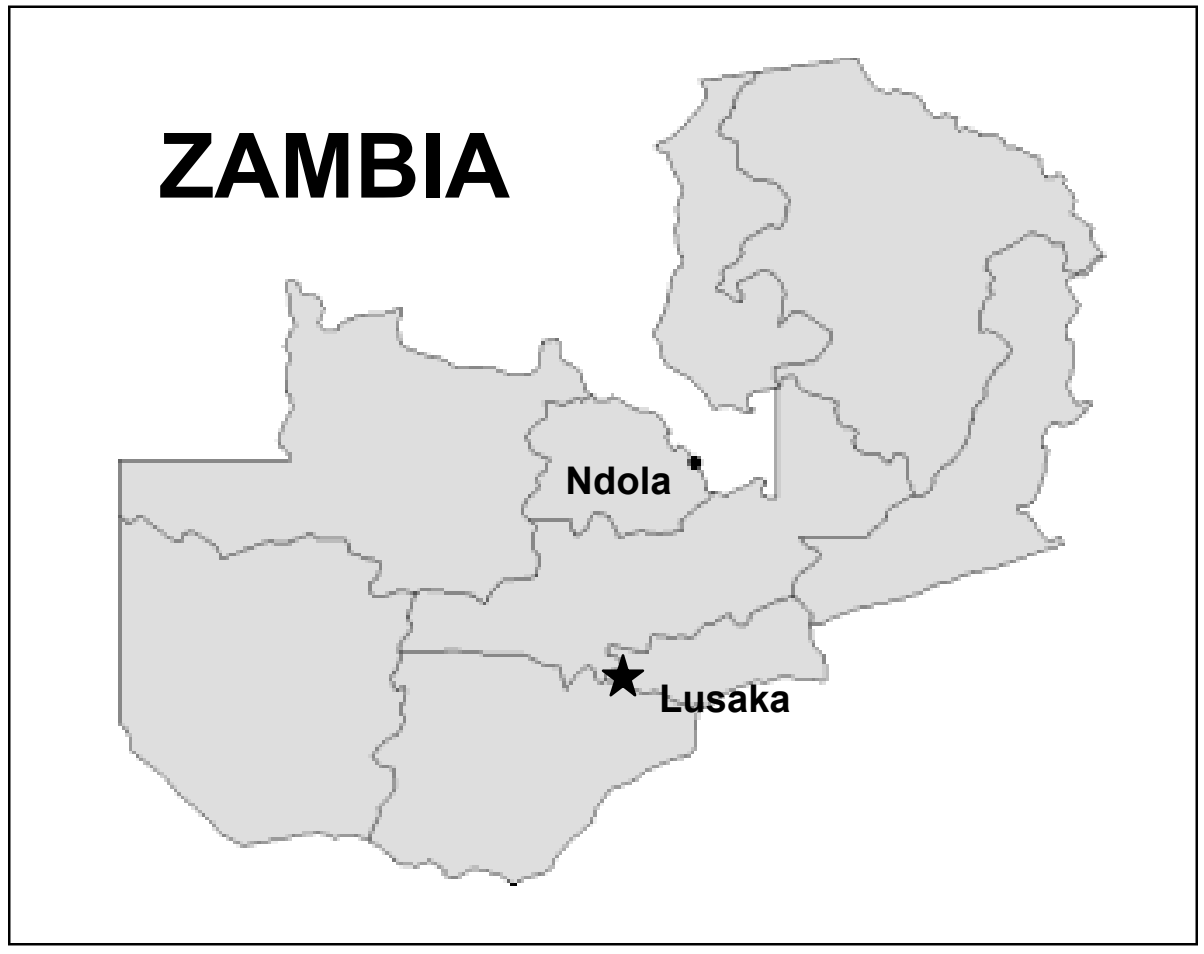

The study setting is a periurban area with a population of approximately 170,000 people living in seven communities served by six DHMT health centers (LINKAGES 2000). HIV prevalence in Ndola is 28.3 percent among adults in the general population and 27.2 percent among women attending ANC (Musonda et al. 1999).

In addition to the six DHMT health centers, local NGOs and public hospitals also provide health facilities in the Ndola District. Hope Humana provides training and mentorship for counselors and has been identified as a potential referral site for VCT for men. The Sisters of the Sacred Heart provides care and support services for HIV-positive women. The potential exists to build a referral network among these NGOs, Ndola General Hospital, and Arthur Davidson Children's Hospital. 
NDP: Midterm Analysis

\section{Study Methods}

\section{Study Design}

The study, followed a pre-/post- intervention design. Baseline surveys were conducted at the six sites during April and May 2000, prior to the introduction of the intervention in May 2000. Second (midterm) and third (final) rounds of data collection were carried out during April and May 2001 and February 2002, respectively. This report analyses the data from the baseline and midterm rounds of data collection to synthesize lessons learned for use in refining the intervention and to provide data for project replication and scale-up.

\section{Data Collection}

\section{Quantitative surveys}

Questionnaires were developed to measure changes in knowledge, attitudes, and practices about $\mathrm{MCH}$, infant feeding, MTCT, VCT, and general HIV issues among mothers identified in clinics and communities, community members, and health workers.

Table 1 summarizes the sample sizes for each of the different data collection methods used at baseline and midterm. Denominator values have not been given in the text that follows unless they differ greatly from the sample sizes indicated below due to missing data or if the data reflect a subsample (e.g., "clinic mothers tested for HIV"). 


\section{${ }^{H} \boldsymbol{X}^{\text {rizons }}$}

Table 1 Sample sizes by data collection method

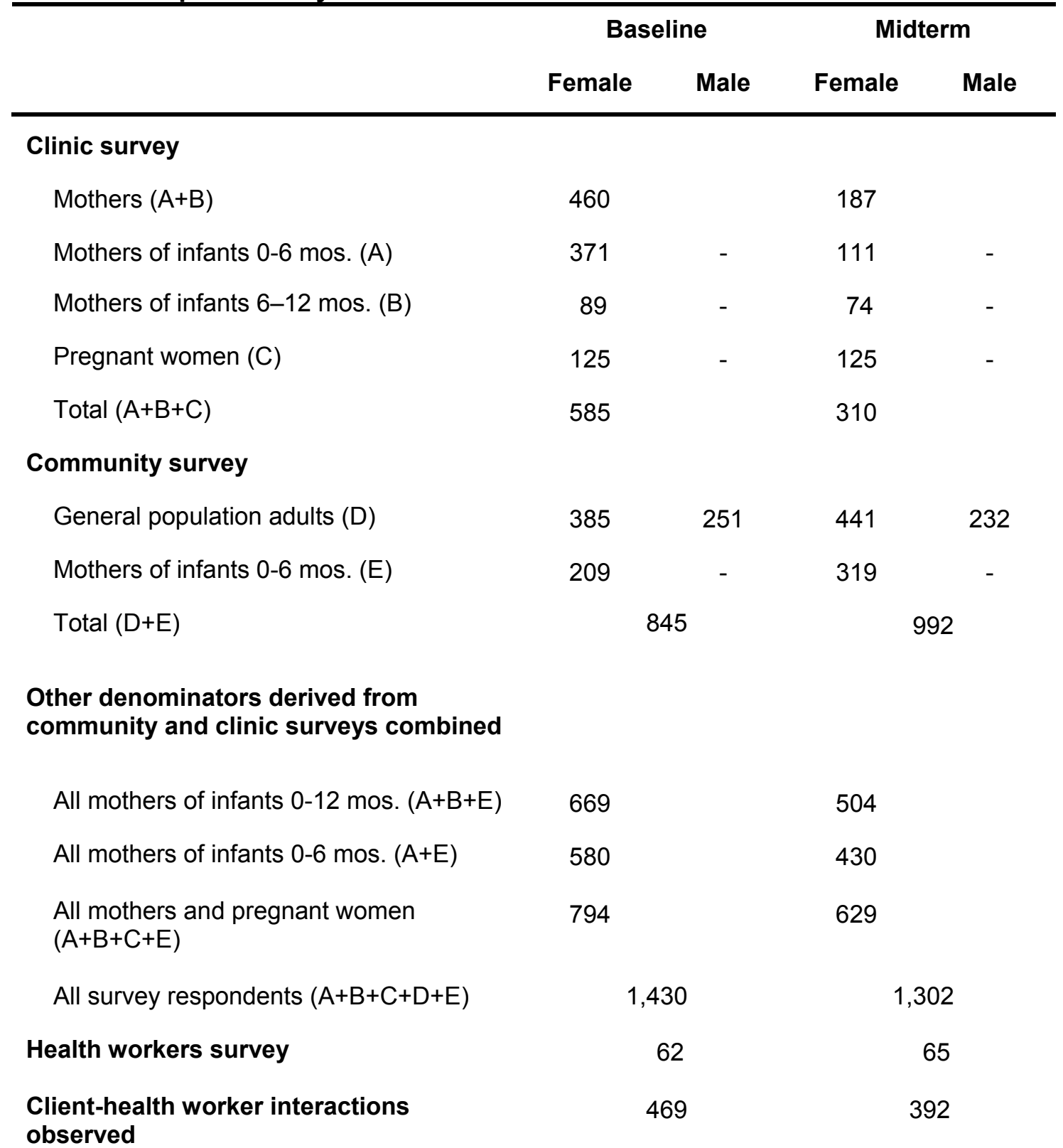


Clinic survey: Pregnant women and mothers of infants less than 12 months old received a questionnaire, administered as an exit interview to every fourth woman using ANC or the infant immunization services at the DHMT clinics during a single week. A total of 586 women were interviewed at baseline, and 312 at midterm. The breakdown of sample sizes according to whether respondents were pregnant or the mother of an infant less than 6 or 12 months old is listed in Table 1.

Community mothers survey: At baseline, 209 mothers of infants less than 6 months old were recruited from the community by asking people if they knew of a neighbor with a young baby. At midterm, 328 mothers of infants under six months old were randomly selected for interviews from 1,608 eligible households identified by the use of census data. The sampling method for mothers of infants 0-6 months in the community changed between baseline and midterm in order to increase sample size.

General community survey: Community members were surveyed at baseline and midterm on their knowledge, attitudes, and behavior regarding HIV and infant feeding. Households were selected at random from the statistical enumeration areas of the census and weighted according to catchment area. All men and women 15 years or older who had spent the previous night in the household were interviewed.

Health workers survey: All clinical and counseling staff at the DHMT clinics and the collaborating community-based organizations were interviewed.

\section{Interaction observations}

Client-health worker interactions were observed at baseline and midterm to assess change in the content and quality of service provided. Counselors and clinicians were trained to observe and grade health workers according to a checklist developed for IFC, ANC, labor, PNC, immunization and growth monitoring, sick child visits, family planning, and VCT services provided. Table 2 indicates the number of interactions that were observed by type of service. 


\section{Hgrizons}

Table 2 Number of client-health worker interactions observed by type of service

\begin{tabular}{lcc}
\hline & $\begin{array}{c}\text { Baseline } \\
(\mathbf{n = 4 6 9 )}\end{array}$ & $\begin{array}{c}\text { Midterm } \\
(\mathbf{n = 3 9 2})\end{array}$ \\
\hline Antenatal care & 56 & 41 \\
Labor & 42 & 20 \\
Postnatal care & 48 & 40 \\
Immunization and growth monitoring & 46 & 41 \\
Infant feeding counseling & 54 & 30 \\
Sick child visit & 51 & 42 \\
Family planning & 46 & 47 \\
Voluntary counseling and testing & 50 & 56 \\
General counseling & 76 & 60
\end{tabular}

\section{Qualitative cohort}

In addition to the surveys and observations, a small cohort of 59 mother-baby pairs was recruited for intensive follow-up quarterly for 12 months after delivery, to follow the experiences of women as they make and implement decisions regarding HIV, pregnancy, and infant feeding. Interviews were completed in May 2002. Data are not yet available.

\section{Data Entry and Analysis}

Quantitative data were double-entered by two data entry clerks using Epi-Info software. Data were imported into SPSS for analysis.

To determine significance, Pearson's chi-squared test of independence was used in most cases. Unless otherwise indicated, an asterisk $(*)$ indicates that the results are statistically significant at or below the 0.05 level, and "ns" indicates results not significant at this level. Where significance of a comparison between the two rounds of data is not indicated, this is because the questions were different between the two survey rounds. 


\section{Results}

\section{Profile of Respondents}

\section{Clinic attendees and community members}

The six NDP clinics surveyed were Kabushi, Kaloko, Lubuto, Masala, Mushili, and Twapia, located in adjacent periurban low-cost housing estates. Labor and delivery services are provided at Lubuto, Masala, and Twapia; however, renovation work at the Lubuto clinic during the data collection period limited the recruitment of respondents from this clinic at baseline, and prevented recruitment entirely at midterm.

Each clinic provides $\mathrm{ANC}, \mathrm{MCH}$, and other outpatient services to local residents of that estate, but catchment areas may overlap. The community survey covered these six estates plus an additional area, Kantolomba, whose residents also seek health care from the Lubuto health center. The respondents for the community surveys were sampled proportionally to the size of the population of each estate

The community survey of adults age 15 and above revealed that the six Ndola estates surveyed have a fairly young population, with 60 percent (baseline) and 51 percent of the men (midterm) and 66 percent (baseline) and 63 percent (midterm) of the women between 15 to 29 years old. The Ndola community is relatively well educated: On average, women had completed seven years of schooling, and men had completed eight years. The mothers interviewed in the community and the clinic surveys were young, with a mean age of approximately 24 years, and this did not change at follow-up. The men surveyed tended to be older and have a higher rate of school attendance and completion than the female survey respondents.

Most mothers and pregnant women (at least 80 percent) interviewed at the clinic were married, but only about half the men and women interviewed in the community survey were married. Few of the mothers in the community and clinic surveys were widowed ( 0.8 percent to 5 percent), with no pregnant woman reporting being widowed at baseline and only two at midterm.

The unemployment rate in Ndola is high. About 15 percent of men and women surveyed in the community were unemployed. Only 25 percent of men and 1 to 5 percent of women were regularly employed full time; 25 percent of men and 9 to 21 percent of women were self-employed. Most pregnant women (69 percent) and women with small children ( 55 to 72 percent) were full-time housewives. The community samples included about 20 percent of males and females who were still in school.

The settlements vary in the quality of housing and access to water and sanitation. Dwellings in Kabushi, Lubuto, Masala, and Mushili are made predominantly of brick and cement with asbestos roofs. Many Kaloko and Twapia residents live in poorer quality housing, with roofing usually of 


\section{Hgrizons}

asbestos or tin. Few households in Twapia, Kaloko, and Kantalomba, which is the poorest of the compounds, have individual water and toilet facilities.

Access to clean water is essential for mothers choosing to replace or supplement breast milk with formula. Table 3 shows the types of water supply in the homes of clinic and community survey respondents from each compound. Although most homes in Ndola District have access to piped water, access varies considerably among settlements. Some of the shared water pipes may be in bad condition or located close to shared pit latrines.

Table 3 Main source of drinking water by estate at midterm for community and clinic respondents

\begin{tabular}{lcccc}
\hline & $\begin{array}{c}\text { Piped water } \\
\text { home } \\
\%\end{array}$ & $\begin{array}{c}\text { Piped water- } \\
\text { shared }\end{array}$ & $\begin{array}{c}\text { Water from } \\
\text { open well }\end{array}$ & $\begin{array}{c}\text { Water from } \\
\text { covered well or } \\
\text { borehole }\end{array}$ \\
\hline Lubuto $(n=194)$ & 91.8 & 8.2 & $\%$ & $\%$ \\
Masala $(n=247)$ & 59.5 & 39.9 & & 0.8 \\
Twapia $(n=132)$ & 13.6 & 65.9 & 9.8 & 10.6 \\
Kabushi $(n=195)$ & 54.9 & 44.6 & & 0.5 \\
Mushili $(n=370)$ & 60.3 & 37.3 & & 2.4 \\
Kaloko $(n=79)$ & 6.3 & 93.7 & & 17.2 \\
Kantolomba $(n=56)$ & 3.6 & 96.4 & & 2.4 \\
Other $(n=29)$ & 41.4 & 20.7 & 20.7 & \\
Total $(n=1,302)$ & 53.1 & 43.0 & & \\
\hline
\end{tabular}

\section{Health workers}

Sixty-two health workers were interviewed at baseline and 65 at midterm from the six DHMT clinics and the collaborating NGOs (Table 4). Most were enrolled midwives; other health professionals interviewed included clinical officers and registered nurses. Table 5 shows that, at baseline, less than one fourth had received previous training in the selected topics of the intervention. According to the midterm results, the greatest increase in reported training occurred for HIV counseling (18 to 52 percent) and sexually transmitted diseases (STDs) (16 to 28 percent). Reported training in lactation management and family planning did not change. Although, as noted 
earlier, 99 trainees attended the sessions, it is possible that staff turnover and poor provider recall of topic names reduced positive responses.

Table 4 Qualifications of health worker respondents

\begin{tabular}{lcc}
\hline Staff member & $\begin{array}{c}\text { Baseline } \\
(\mathbf{n}=\mathbf{6 2}) \\
\mathbf{\%}\end{array}$ & $\begin{array}{c}\text { Midterm } \\
(\mathbf{n}=\mathbf{6 5}) \\
\mathbf{\%}\end{array}$ \\
\hline Enrolled midwives & 76 & 69 \\
Clinical officers & 11 & 15 \\
Registered nurses & 8 & 8 \\
Other & 5 & 8
\end{tabular}

Table 5 Reported training of health worker respondents

\begin{tabular}{lcc}
\hline Have you received training in...? & $\begin{array}{c}\text { Baseline } \\
(\mathbf{n = 6 2}) \\
\%\end{array}$ & $\begin{array}{c}\text { Midterm } \\
(\mathbf{n}=65) \\
\%\end{array}$ \\
\hline HIV counseling & 18 & 52 \\
FP & 23 & 28 \\
STDs & 16 & 28 \\
Lactation management & 10 & 11
\end{tabular}




\section{Herizons}

\section{MTCT Knowledge}

\section{Clinic and community respondents}

Tables 6 to 9 present data indicating the levels of awareness of modes of MTCT and its prevention among the general community.

The possibility of HIV transmission from a mother to her child during pregnancy and breastfeeding was well known in the community even before the intervention. Table 6 shows that after the initiation of the intervention, community awareness of all three modes of transmission increased, with the largest gains in awareness of transmission at delivery and through breastfeeding. At the midterm assessment, breastfeeding was the most widely known route of mother-to-child transmission.

Table 6 Knowledge of MTCT among community respondents

\begin{tabular}{lccc}
\hline $\begin{array}{l}\text { Knowledge that HIV can be } \\
\text { transmitted during: }\end{array}$ & $\begin{array}{c}\text { Baseline } \\
\mathbf{n}=\mathbf{8 4 5} \\
\%\end{array}$ & $\begin{array}{c}\text { Midterm } \\
\mathbf{n = 9 9 2} \\
\mathbf{\%}\end{array}$ & Significance \\
\hline Pregnancy & 68.5 & 72.7 & $*$ \\
Delivery & 17.3 & 43.3 & $*$ \\
Breastfeeding & 57.8 & 77.0 & $*$ \\
${ }^{*} p \leq .05$ & & &
\end{tabular}

Data from the clinic surveys indicate a dramatic decline in the proportion of respondents replying that "nothing can be done" to prevent MTCT during pregnancy, from 68.8 percent at baseline to 8.1 percent at midterm. Tables 7 and 8 show that the message that HIV transmission from mother to child can indeed be prevented had diffused to reach the community at large by midterm, although the increase in the proportion of respondents who responded that they "do not know" suggests that many community members remain unaware of the details of how MTCT can be prevented. By midterm, several methods of reducing risk of MTCT-abstinence, condoms, and management of labor-were well known in the community, yet there is still a need for education to increase knowledge of MTCT prevention options in the community.

Short-course ARVs may be mentioned by the counselor during pre- or post-test counseling, and health workers may advise mothers that medications can be purchased privately. Neither nevirapine nor AZT regimens are provided through the NDP, so they currently remain out of reach of most of the community. The surveys revealed that some community members are already independently aware of the possibility of using these drugs during pregnancy and delivery to prevent transmission, but the intervention equipped them with knowledge of accessible PMCT methods 
that were within reach and available within the communities. The Zambian Ministry of Health is currently making an effort to provide ARVs for prevention of mother-to-child transmission within the public health system.

Table 7 Knowledge of MTCT during pregnancy among community respondents

What can be done to reduce

MTCT during pregnancy?

Baseline
$\mathrm{n}=\mathbf{8 4 5}$
$\mathrm{n}(\%)$

Nothing can be done

Take medicine

Abstain from sex

Use condoms/safer sex

Better nutrition

Don't know

${ }^{*} p \leq .05$

\section{7}

7.6

0.1

7.8

3.1

12.1
Midterm

$\mathrm{n}=992$

n (\%)
Significance

13.9

4.9

29.9

26.5

6.8

20.3

Table 8 Knowledge of MTCT during delivery among community respondents

What can be done to reduce MTCT during delivery?

Baseline
$\mathbf{n}=\mathbf{8 4 5}$
$\%$

Nothing can be done

Take medicine

Cesarean section

Appropriate management during labor ${ }^{\mathrm{a}}$

Don't know

60.5

3.0

1.7

7.9

15.0

\section{Midterm \\ $\mathrm{n}=992$ \\ $\%$}

Significance

21.2

0.9

4.3

46.5

30.1

a At midterm, this was phrased "seek good management during delivery."

${ }^{*} p \leq .05$ 


\section{Hgrizons}

Table 9 shows that among community members asked what could be done to prevent MTCT

during breastfeeding, the percentage responding that "nothing can be done" decreased dramatically at midterm from 32 to 6 percent. Respondents citing early weaning and/or replacement feeding as a method to reduce MTCT increased significantly across all respondents, but there was no significant change in the respondents suggesting exclusive breastfeeding as an MTCT reduction method.

However, when these data are disaggregated, a slight increase can be detected among the mothers of infants less than 6 six months old in the community who are aware of exclusive breastfeeding as a method of reducing MTCT (from 0 percent at baseline to 2.8 percent at midterm). This

proportion is still very low and calls for increased awareness of the role of exclusive breastfeeding in reducing MTCT. Meanwhile, the number of respondents who suggested condoms as a method of MTCT reduction during breastfeeding increased.

\section{Table 9 Knowledge of MTCT during breastfeeding among all community respondents}

\begin{tabular}{|c|c|c|c|}
\hline $\begin{array}{l}\text { What can be done to reduce MTCT } \\
\text { during breastfeeding? }\end{array}$ & $\begin{array}{c}\text { Baseline } \\
\mathrm{n}=845 \\
\%\end{array}$ & $\begin{array}{c}\text { Midterm } \\
\mathrm{n}=992 \\
\%\end{array}$ & Significance \\
\hline Nothing can be done & 31.8 & 5.9 & * \\
\hline $\begin{array}{l}\text { Give breast milk only/no feeds up to } 6 \\
\text { mos. (i.e., exclusive breastfeeding) }\end{array}$ & 0.8 & 1.5 & ns \\
\hline $\begin{array}{l}\text { Early weaning/give infant formula/cow's } \\
\text { milk }\end{array}$ & 52.0 & 74.4 & * \\
\hline $\begin{array}{l}\text { Get tested; if HIV+ make informed } \\
\text { decision }\end{array}$ & 1.1 & 3.4 & * \\
\hline Use condoms & 1.5 & 11.2 & * \\
\hline Get early treatment for illnesses & 1.7 & 3.6 & * \\
\hline Take medicines & 0.8 & 1.2 & ns \\
\hline
\end{tabular}

\section{Health workers}

Since the introduction of the intervention, health workers appear to be moving away from the recommendation that mothers use alternative feeds from birth (see Table 10). More health workers are suggesting other options for PMCT during breastfeeding, including VCT and condom use. The 
most significant increase was observed among those who suggested early weaning. Meanwhile, little change was observed among those suggesting better health-seeking behavior and nutrition for mother and infant.

Table 10 Health workers' knowledge of MTCT prevention during breastfeeding

\begin{tabular}{|c|c|c|c|}
\hline $\begin{array}{l}\text { What can be done to reduce MTCT } \\
\text { during breastfeeding? }\end{array}$ & $\begin{array}{c}\text { Baseline } \\
\mathrm{n}=62 \\
\%\end{array}$ & $\begin{array}{c}\text { Midterm } \\
\mathrm{n}=65 \\
\%\end{array}$ & Significance \\
\hline $\begin{array}{l}\text { Mothers should stop breastfeeding, } \\
\text { use alternative feeds }\end{array}$ & 59.7 & 40.0 & * \\
\hline $\begin{array}{l}\text { Mothers should be tested and make an } \\
\text { informed decision }\end{array}$ & 6.5 & 13.8 & ns \\
\hline Exclusive breastfeeding & 17.7 & 20.0 & ns \\
\hline Early weaning & 21.0 & 36.9 & * \\
\hline Nothing & 3.2 & 0.0 & $\mathrm{~ns}^{\mathrm{a}}$ \\
\hline Use condoms & 3.2 & 10.8 & $\mathrm{~ns}^{\mathrm{a}}$ \\
\hline Get early treatment for illness & 16.1 & 13.8 & ns \\
\hline Take medicines & 1.6 & 4.6 & $\mathrm{~ns}^{\mathrm{a}}$ \\
\hline Better nutrition for both mother and baby & 12.9 & 7.7 & ns \\
\hline Other & 9.7 & 10.8 & ns \\
\hline Don't know & 4.8 & 3.1 & $\mathrm{~ns}^{\mathrm{a}}$ \\
\hline
\end{tabular}

The proportion of health workers who said they felt technically competent to provide IFC, although relatively high at baseline ( 73 percent), did not improve significantly at midterm (77 percent). Evidence from the observed sessions suggests that MTCT and IFC are being integrated into counseling sessions. Observation of post-test counseling sessions at baseline revealed that health workers satisfactorily discussed MTCT with HIV-positive pregnant women during approximately half the sessions (seven out of thirteen), rising to four out of five sessions observed at midterm. Health workers engaged mothers in discussion of infant feeding choices in only four out of twelve 


\section{Hgrizons}

post-test counseling sessions at baseline, and by midterm, infant feeding options were satisfactorily discussed at all five sessions observed.

Although the small numbers of sessions observed make it difficult to assess the significance of these changes, it appears that IFC and discussion of MTCT may be improving. This is a particularly important finding since a significantly increased percentage of health workers reported that they have been responsible for providing care to an HIV-positive pregnant woman (48 percent at baseline to 66 percent at midterm).

\section{Voluntary Counseling and Testing}

All women attending MCH clinics are offered the opportunity of confidential VCT, in order to receive information about their HIV status and make an informed infant feeding decision. VCT also helps women review their HIV risk factors and develop risk reduction plans.

\section{Awareness, uptake, and perceptions of VCT}

Among all respondents, awareness of the confidential, free VCT services available at the health centers increased significantly, from 45 percent at baseline to 75 percent at midterm. Table 11 shows that the number of respondents who have ever had an HIV test remains low among all groups, although significant increases are detected among groups who have most recently been exposed to clinic counseling (pregnant women and mother of young infants). 
NDP: Midterm Analysis

Table 11 HIV testing among community and clinic

\begin{tabular}{|c|c|c|c|}
\hline Had an HIV test & $\begin{array}{c}\text { Baseline } \\
\%(n)\end{array}$ & $\begin{array}{c}\text { Midterm } \\
\% \text { (n) }\end{array}$ & Significance \\
\hline \multicolumn{4}{|l|}{ Clinic } \\
\hline Mothers of infants $<6$ mos. & $5.7(371)$ & $14.4(111)$ & * \\
\hline Mothers of infants $6-12$ mos. & $6.7(89)$ & $14.9(74)$ & ns \\
\hline Pregnant women & $3.2(125)$ & $12.8(125)$ & * \\
\hline \multicolumn{4}{|l|}{ Community survey } \\
\hline Adult males & $6.8(250)$ & $5.2(232)$ & ns \\
\hline Adult females & $3.9(384)$ & $5.7(441)$ & ns \\
\hline Mothers of infants $<6 \mathrm{mo}$ & $5.3(209)$ & $15.0(319)$ & * \\
\hline Total (all respondents) & 5.2 & 9.8 & \\
\hline
\end{tabular}

When presented with the statement that "VCT reduces worries," community respondents showed a significant reduction among those who "completely agreed" with the statement, from 37 percent at baseline to 27 percent at midterm. Meanwhile, those who "completely disagreed" remained at approximately half. These findings indicate that VCT is still perceived as a source of stress and this view may explain why service uptake remains low.

\section{Disclosure and partner testing}

Although disclosure of HIV test results to someone was high among those who had tested before the intervention, less than two-thirds of females who had disclosed reported that they had chosen to disclose to their spouse (Table 12). At midterm, the proportion of respondents reporting that they had disclosed their HIV status to their spouse following testing increased significantly to 93 percent. 


\section{Hgrizons}

Table 12 Reported HIV status disclosure, all female respondents (clinic and community)

\begin{tabular}{|c|c|c|c|}
\hline & $\begin{array}{l}\text { Baseline } \\
\quad \%(n)\end{array}$ & $\begin{array}{l}\text { Midterm } \\
\quad \%(n)\end{array}$ & Significance \\
\hline All female respondents & $\begin{array}{l}4.8(1,179) \\
\text { tested }\end{array}$ & $\begin{array}{l}9.2(1,257) \\
\text { tested }\end{array}$ & \\
\hline Did you receive your test results? & $77.2(57)$ & $82.8(116)$ & ns \\
\hline $\begin{array}{l}\text { Did you tell anyone the result of your } \\
\text { test? }\end{array}$ & $86.4(44)$ & $91.7(96)$ & $\mathrm{ns}^{\mathrm{a}}$ \\
\hline $\begin{array}{l}\text { Did you tell your spouse the result of } \\
\text { your test? }\end{array}$ & $63.2(38)$ & $93.2(88)$ & * \\
\hline $\begin{array}{l}n s=\text { not significant at this level } \\
{ }^{a} \text { Fisher's Exact Test used } \\
{ }^{*} p \leq .05\end{array}$ & & & \\
\hline
\end{tabular}

Although the data show that men and women were equally likely to be tested (Table 11), women were twice as likely to report that their partner had been tested (12 out of 23 tested at midterm, 52 percent) than men ( 3 out of 12 tested, 25 percent), indicating that communication and disclosure remain difficult between men and women.

\section{Antenatal and Postnatal Care}

The NDP intervention aimed to strengthen the essential care package offered to mothers during pregnancy, delivery, and the postnatal period by improving clinic infrastructure, providing additional supplies, and increasing the number and building the capacity of health workers. However, data reported in the surveys and observed from client-health worker interactions (refer to Table 2 for session types) show that logistics problems hampered the fulfillment of some of these intentions, as described below.

\section{Attendance}

ANC attendance in Zambia is generally high: In the 1996 DHS, 98 percent of women had received antenatal care at least once during pregnancy. The NDP community survey showed that the percentage of women reporting that they had attended ANC during their current or last pregnancy rose significantly from 91 percent at baseline to 96 percent at midterm. There was no significant change in any of the surveys in the proportion of women who reported attending ANC four times or more. This remained at approximately 71 percent for community and clinic mothers combined. 


\section{Routine testing and services}

Although laboratory infrastructure for hemoglobin and syphilis testing improved under NDP, little change was observed in the level of testing carried out between baseline and midterm. Hemoglobin testing was offered by health workers at 12 percent of the 41 observed ANC sessions at baseline $(\mathrm{n}=56)$ and 13 percent at midterm $(\mathrm{n}=41)$ (see Table 2 for denominators).

The baseline and midterm surveys of all mothers and pregnant women showed that those who reported undergoing hemoglobin testing during their current or last pregnancy increased significantly from 11 percent to 33 percent. Reported malarial prophylaxis during pregnancy increased from 7 percent to 18 percent. However, these results cannot be attributed to the NDP alone because the Tropical Disease Research Center (TDRC) was carrying out concurrent research on hemoglobin and malaria in Masala and Twapia clinics.

The percentage of women who reported receiving syphilis testing during their current or last pregnancy was 25 percent at baseline and 22 percent at midterm. Testing remained limited due to a lack of reagents. Adequate numbers of syphilis testing kits were not supplied until July 2001, which was after the midterm data collection.

The percentage of observed ANC sessions in which health workers prescribed iron folate did not increase significantly (from 7 percent at baseline to 10 percent) at midterm). Among all mothers and pregnant women, those reporting having received iron folate in the current or previous pregnancy increased from 15 percent to 38 percent (significant in all groups except mothers of 6-12 month-old babies). One reason for this increase may be that an ad hoc supply of iron folate became available sometime before the midterm survey.

\section{Infection prevention procedures}

Sterile gloves were used during 64 percent of labor and delivery sessions observed at baseline, rising to 75 percent at midterm. Health workers were observed to change gloves between procedures in 17 percent of the baseline sessions and 15 percent at midterm. While piped water was available at most sessions (67 percent at baseline, 100 percent at midterm), the degree to which health workers were observed to wash their hands between procedures, such as examining a woman or delivering a baby, decreased from an already low level of 26 percent to only 15 percent of sessions.

\section{Postnatal care}

Health workers checked for signs of postnatal anemia at 83 percent of baseline sessions, and 90 percent at midterm. Health workers prescribing vitamin A at postnatal consultations for mothers who had not previously received any increased from 33 percent in the initial observations to 61 percent at subsequent observations. 


\section{Hgrizons}

\section{Infant Feeding}

\section{Infant feeding intentions before delivery}

Pregnant women were asked about their intentions for feeding their infant during the first few months after birth. Exclusive breastfeeding was the response of 79 percent of pregnant clinic attendees at baseline, rising significantly to 97 percent at midterm. ${ }^{1}$ Almost all the mothers interviewed were feeding breast milk to their infants at some point during the first year.

\section{Infant feeding practices at delivery}

Women giving birth in the health centers covered by the NDP may have the assistance of a health worker recently trained by NDP in MTCT risk-reduction strategies during and after delivery as compared to women delivering at home or hospital, outside of the intervention. Table 13 shows that the number of women who reported giving birth in a health center increased between baseline and midterm, compared with those who gave birth at home or in a hospital. Among mothers of infants less than 6 months old (from both clinic and community surveys), 48 percent reported giving birth at a health center at baseline and 61 percent at midterm. This may have been linked to the new maternity facilities at Lubuto.

\begin{tabular}{|c|c|c|}
\hline Where was the infant delivered? & $\begin{array}{c}\text { Baseline } \\
(n=579) \\
\%\end{array}$ & $\begin{array}{c}\text { Midterm } \\
(n=430) \\
\%\end{array}$ \\
\hline At home & 22.6 & 17.7 \\
\hline In a health center & 48.4 & 61.2 \\
\hline In a hospital & 28.8 & 20.7 \\
\hline Other & 0.2 & 0.5 \\
\hline
\end{tabular}

It is crucial that the mother gets support in the initiation of breastfeeding, ideally from a health worker immediately after delivery. Immediate skin-to-skin contact between mother and infant following birth is encouraged for all women, regardless of HIV status, to promote bonding and prevent heat loss by the infant. Early initiation of breastfeeding, when the baby's sucking reflexes are very strong, has the added advantage of reducing postpartum bleeding. For mothers choosing to

\footnotetext{
${ }^{1}$ The baseline question was phrased "How do you plan to feed the baby?" and the midterm question was "How do you plan to feed the baby in the first few months?"
} 
breastfeed their infants, initiation of breastfeeding within one hour of birth is recommended to ensure that good breastfeeding practices are established early and under the guidance of a trained health worker. For mothers choosing to give their infants replacement feeds instead of breast milk, a health worker can demonstrate proper preparation of infant formula.

Among clinic and community mothers of infants less than 6 months old, women reporting that they received assistance to start breastfeeding increased from 36 percent to 41 percent at midterm, and of these, there was a large increase in the percentage of women reporting that this assistance came from a health worker: from 67 percent $(n=240)$ to 84 percent $(n=207)$.

At baseline, 59 percent of clinic and community mothers of infants less than 6 months old reported being given their child to hold within one hour of birth, to promote bonding and prevent heat loss by the infant; this rose to 87 percent at midterm. ${ }^{2}$ Although this question may have been understood as referring to initiation of breastfeeding rather than just being given the child to hold against the breast, the response seems to indicate an upward trend in getting a newborn into a mother's arms.

At baseline, 58 percent of these mothers reported that their baby started sucking less than one hour after birth. Midterm findings indicated an increase to 82 percent of mothers reporting early initiation of breastfeeding. Results for mothers of infants less than 12 months old attending clinics show similar findings, rising from 52 percent at baseline to 76 percent at midterm.

\section{Infant feeding practices before 6 months of age}

HIV test results are confidential and not indicated on a mother's ANC health records. Health workers assisting a mother at antenatal, delivery, or postnatal stages, including IFC, will not know the mother's HIV status unless she chooses to disclose it. The results that follow are therefore disaggregated according to whether women knew their HIV status or not, rather than actual HIV status, which was also unavailable to interviewers.

Women who do not know their HIV status are counseled to exclusively breastfeed their infants for the first six months, in accordance with Zambian infant feeding policy and international guidelines on infant feeding in Africa. These recommendations are based on a balance between the risks of HIV transmission from breast milk and the risks of inadequate nutrition or unhygienic preparation of replacement feeds without breast milk. Exclusive breastfeeding remains the safest option for infants of women who are HIV-negative or those who do not know their HIV status. Regardless of whether a mother tests negative or positive, mixed feeding is not recommended during the child's first 6 months of life. For an HIV-negative mother, mixed feeding could increase the exposure of her child to pathogens or inadequate nutrition through improperly prepared breast milk substitutes. For HIV-positive mothers, mixed feeding could have the added negative effect of increasing the risk of her transmitting HIV to her infant through breastfeeding.

\footnotetext{
${ }^{2}$ At baseline, the question was phrased, "How long after birth were you given (name) to hold and put to the breast ?" At midterm the question was phrased, "How long after birth were you given (name) to hold (skinto-skin contact)?"
} 


\section{Hgrizons}

Table 14 shows that the safer practice of exclusive breastfeeding increased among all mothers of infants less than 6 months old who did not know their HIV status. Although baseline rates were higher than anticipated, by midterm this practice had been adopted by as many as 85 percent of clinic attendees, who were more likely to have been exposed to the enhanced counseling. This encouraging result shows that these women are increasingly following the safer practice of giving their infants only breast milk. Furthermore, in the community exclusive breastfeeding rates increased from 56 percent to 76 percent. Meanwhile, among all mothers in the community and the clinics, the riskier practice of mixed feeding declined.

The implication of these trends is that even as NDP increases women's knowledge that HIV can be passed from a mother to her child through breastfeeding, good breastfeeding practices are not being eroded among those women who do not know their HIV status. Few mothers at baseline and midterm reported that they were not breastfeeding or choosing to feed exclusively by replacement.

Table 14 Current feeding practices among clinic and community mothers of infants less than 6 months old who do not know their HIV status

\begin{tabular}{lcc}
\hline & $\begin{array}{c}\text { Baseline } \\
\%\end{array}$ & $\begin{array}{c}\text { Midterm } \\
\%\end{array}$ \\
\hline $\begin{array}{l}\text { Clinic mothers of children less than } \mathbf{6} \\
\text { mos. old, HIV status unknown }\end{array}$ & $(\mathbf{n}=\mathbf{3 5 2})$ & $(\mathbf{n}=\mathbf{9 7})$ \\
Exclusive breastfeeding & 71 & 85 \\
Mixed & 28 & 15 \\
Exclusive replacement / not breastfeeding & 1 & 0 \\
$\begin{array}{l}\text { Community mothers of children less than } \\
\mathbf{6} \text { mos. old, HIV status unknown }\end{array}$ & $(\mathbf{n}=\mathbf{1 9 8 )}$ & $\mathbf{( n = 2 7 9 )}$ \\
Exclusive breastfeeding & 56 & 76 \\
Mixed & 44 & 23 \\
Exclusive replacement / not breastfeeding & 0 & 1
\end{tabular}

Interpreting the infant feeding data for women who know their HIV status is more difficult. As noted above, to honor the mother's confidentiality, the interviewers did not ask for HIV status, so it is therefore impossible to link a mother's HIV status to her infant feeding practices. In addition, different health workers may give the mother different advice on infant feeding, depending on whether she has disclosed her HIV status to them.

Although the sample size for women who had received their HIV test results is small and changes are not significant, the data suggest that mothers who know their HIV status are moving away from 
mixed feeding toward the recommended practice of giving breast milk exclusively for the first six months of the child's life. At baseline, approximately one third of these 24 mothers of infants under 6 months who knew their status reported mixed feeding, while two thirds reported exclusive breastfeeding. At midterm, mixed feeding dropped to approximately one quarter, and exclusive breastfeeding increased to approximately three quarters. Avoiding breastfeeding and feeding exclusively by replacement remained an unpopular option among these mothers, implying that even mothers who knew their HIV-positive status were unwilling or unable to totally refrain from breastfeeding.

Community mothers of infants 0 to 6 months old were asked how often they were breastfeeding their children at the time of interview. At baseline, 68 percent reported breastfeeding on demand and 20 percent reported feeding each time the child cried. At midterm, mothers were asked how many times they had breastfed in the past 24 hours; 46 percent reported 8 to 12 times and 45 percent reported a frequency of 13 or more times. Only 4 percent of these mothers interviewed at midterm reported that their infants had drunk something from a bottle with a teat the day or the night before. Although the change in question wording prevents direct comparison, it is clear that frequent breastfeeding remains the prevailing pattern.

\section{Infant feeding practices after 6 months of age}

Once an infant reaches about 6 months of age, the infant's nutritional needs change and breast milk alone no longer adequately satisfies requirements. Standard recommended practice is to encourage the mother to begin to gradually introduce appropriate complementary semi-solid or solid foods while continuing to breastfeed until the child is at least 2 years old. Formative research completed in the NDP catchment area identified locally available and feasible complementary foods to be given to infants beginning around 6 months. NDP providers used this information to counsel mothers about how to feed their babies after 6 months of age.

The morbidity and mortality risks associated with replacement feeding decrease significantly after the first few months of life (WHO 2000; White 1999). For HIV-positive mothers, the risks of HIV transmission may begin to outweigh breast milk's nutritional benefits, and researchers have suggested early and abrupt weaning as a potential intervention to reduce MTCT (Bertolli 1996; Ekpini 1997). Studies currently being conducted to examine the feasibility of this intervention have not yet yielded recommendations. NDP health workers are not urging women to wean early, and it is left open for HIV-positive women who are breastfeeding to decide when to stop breastfeeding.

Although the survey data showed that women's knowledge of early weaning as a possible means to reduce likelihood of HIV transmission had in general increased (see Table 9 above), the data indicate that almost 100 percent of the mothers of infants between 6 and 12 months old at the clinics were still breastfeeding at the time of interview at both baseline and midterm surveys. Knowledge of HIV status does not appear to affect the practice of continuing to give breast milk beyond 6 months in the NDP catchment area, most likely for both economic and social reasons and to avoid the stigma associated with not breastfeeding. 


\section{Herizons}

The timely (six months) initiation of complementary feeding ${ }^{3}$ among infants 6 to 12 months old whose mothers were interviewed at clinics increased from a rate of 72 percent at baseline to 88 percent at midterm. Of these infants, those receiving at least two of the recommended complementary foods ${ }^{4}$ have increased from 26 percent at baseline to 39 percent at midterm.

Giving maize porridge (nshima) as complementary food is common in the NDP area. To ensure that an older infant is getting adequate nutrition, NDP recommends that mothers enrich this food to increase the variety of nutrients and the amount of calories it contains. The proportion of mothers of babies 6 to 12 months old who reported using pounded kapenta (a local fish) to enrich their infant's food changed from 8 percent at baseline to 13 percent at midterm. Those enriching their infant's food using milk increased significantly from 20 percent at baseline to 35 percent at midterm, while those using sugar increased from 46 to 56 percent. ${ }^{5}$ Formative research reveals groundnuts as another locally available and appropriate ingredient; the surveys found that 71 percent of mothers were correctly enriching their infant's food with groundnuts at baseline, remaining at 74 percent at midterm.

\section{HIV Prevention and Care I ssues}

\section{Sexual behavior}

The prevention of new HIV infection remains one of the most important components of the MTCT package. The NDP has initiated interventions to prevent HIV infection among pregnant women and their partners, including HIV prevention education and counseling for ANC clinic attendees. Results at midterm indicated that, among all community mother respondents, condom use at last sex with regular partner remained stable at approximately 13 percent $(n=209)$.

Although baseline levels were originally low, the number of community mothers reporting two or more sexual partners in the last 12 months decreased significantly from 9 percent to 3 percent $(\mathrm{n}=$ 209). The data also suggest that between the baseline and the midterm surveys, other community members have also reduced their risk of HIV infection from sex with more than one partner in the last 12 months. Among all female community respondents (including mothers), 84 percent ( $\mathrm{n}=$ 594) reported not more than one sexual partner in the past 12 months at baseline, rising significantly to 88 percent $(n=760)$ at midterm, suggesting that preventive sexual behavior has improved among women. Meanwhile among men, a smaller change was observed, which was not statistically significant (69 percent at baseline to 72 percent at midterm).

\footnotetext{
${ }^{3}$ At least one semi-solid or solid food given to the infant along with breast milk in the 24 hours before the survey.

4 'Recommended complementary foods are identified as nshima (maize porridge) and other semi-solid starch foods (LINKAGES 1999).

${ }^{5}$ The promotion of vitamin A-fortified sugar, which occurred during the reporting period, could have increased the use of sugar as an enrichment of baby's food.
} 
Communication about HIV risk reduction remains difficult. Community mothers reporting that they had ever discussed personal HIV risks or concerns with anyone did not change significantly, from 55 percent at baseline to 57 percent $(\mathrm{n}=209)$ at midterm. Among those community mothers who had ever discussed these concerns with anyone, little change was observed in those who raised the issues specifically with their partner, from 62 percent at baseline to 60 percent at midterm.

\section{Care and support of PLHA}

Although the project aimed to emphasize the development of a referrals network, including NGOs to meet the care and support needs of PLHA, referrals currently appear to be going from the NGOs only to the clinics for MTCT risk reduction, and from the clinics to the tertiary referral centers for more advanced medical treatment that cannot be provided at the NDP clinics. Referrals from the medical centers to the NGOs for social indications to meet the care and support needs of PLHA do not appear to be taking place. (See data in Appendix 2.) 


\section{Hgrizons}

\section{Discussion and Recommendations}

\section{Study Limitations}

The NDP was conducted as a pre-/post-intervention study, without a comparison area, and without tools to measure the strength of the intervention, whose coverage was found to be patchy. Without such tools, it is impossible to attribute the changes observed at midterm to the NDP intervention itself, especially in the presence of previous and concurrent initiatives to promote VCT and HIV risk-reduction behaviors and to motivate women to change their health-seeking behavior. The high exclusive breastfeeding levels reported in the community at baseline (56 percent, compared with the Copperbelt urban rate of 31.8 percent reported in Zambia DHS 1996) must be acknowledged. However, the NDP midterm results demonstrate encouraging trends, including improved breastfeeding practices and risk reduction behaviors:

\section{MTCT Knowledge I mproved But Still I ncomplete}

At midterm, NDP results showed that community awareness of the modes of MTCT had improved. However, community members were still largely unaware of methods to prevent transmission from mother to infant via all three modes. Although infant feeding counselors did not stress ARVs, some community members were independently aware of the possibility of taking medicines to reduce MTCT.

Continued capacity building among health workers to educate community members about prevention options is recommended, including ARVs as they become available. Infrastructure should be strengthened with a view to future ARV provision for the prevention of MTCT through Ministry of Health systems.

\section{Breastfeeding Practices I mproved}

The NDP demonstrated that increasing women's knowledge of MTCT did not appear to erode good breastfeeding practices. Despite women's knowledge that HIV may be transmitted through breast milk, many mothers evaluated their relative risks and benefits and made infant feeding decisions that favored the health of their infant. Moreover, midterm results show that immediate skin-to-skin contact after birth and early initiation of breastfeeding under trained guidance increased.

Among women who did not know their HIV status and among women who were aware of their status, the recommended practice of exclusive breastfeeding up to the age of 6 months increased and the riskier practice of mixed feeding decreased. Both of these trends are of benefit to all women, whether HIV-positive or -negative. However, even among women who knew that they were HIV-positive, few women are choosing to completely discontinue breastfeeding and feed 
exclusively by replacement, suggesting that stigma and the cost associated with replacement feeding continue to be important disincentives.

For infants older than 6 months, complementary feeding practices improved. Despite mothers' improved awareness of early weaning or replacement feeding as ways to reduce the risks of HIV transmission, almost all mothers were still breastfeeding at 12 months, suggesting that they lacked the guidance, support, and/or resources to protect their infant from continued exposure.

Further development of a tool to monitor and document IFC service delivery and women's decision making is still required to obtain further data on how counseling affects a woman's infant feeding decision making. Health worker training should continue to include the provision of IFC at individual sessions in ANC clinics, and community-level infant feeding education should be emphasized. Comprehensive systems to monitor infant feeding counselors and meet their supervision and ongoing continued professional development needs will be required. Other areas indicated for further research and strengthening include the possibility of counselors providing support on abrupt weaning to HIV-positive women and on complementary feeding to all women.

\section{Partner Communication and Sexual Risk Reduction Need Further Emphasis in the Community}

Women continue to be at risk of HIV infection during the perinatal period due to the behavior of their partners. Despite training for health workers on how to run health education activities throughout the clinics and beyond to promote discussion of HIV risk reduction, levels of partner communication and condom use have not markedly improved within the community. Investigation is needed into new ways of protecting married women from HIV infection during the perinatal period by addressing the risk behavior of their husbands. Research should explore innovative ways to reach men, including community education campaigns and couple counseling, to educate about the importance of safer sex during pregnancy and lactation.

\section{VCT Uptake and Disclosure Remain Low Despite Service I mprovements}

Supply-side factors were successfully overcome to set up the VCT service, demonstrating that the logistical requirements can be met. However, VCT uptake remained low, indicating that demandside factors among clinic attendants and in the community remain to be addressed. VCT is still viewed as a source of additional stress; even though women are increasingly aware of services, they may not wish to use them. Service providers should focus on how to increase demand by drawing attention to the benefits of testing (the provision of information that enables people to make decisions and gain access to care) and examining whether further service improvements are required to reduce disincentives to uptake (for example, strengthen specimen transport and logistics systems to reduce waiting to receive results).

Disclosure to partners increased but remained low. Counseling for women should focus on providing them with skills and support to discuss HIV risk reduction and facilitate disclosure 


\section{Herizons}

(including assessing the safety of disclosure) with their partner. Couple counseling and programs to increase the impact of individual counseling (e.g., community-wide education programs) should be explored.

\section{Routine ANC Services Also Need Additional Resources}

Inputs including new infrastructure, training, and supplies for the enhanced services were made available for the enhanced program but not for routine ANC services, leading to program weaknesses. NDP has not been able to provide a comprehensive $\mathrm{MCH}$ package because the availability of basic supplies is erratic. Future programs should strengthen supply and logistics systems for all routine ANC resources in addition to providing an enhanced service for selected program components.

Since anemia and STIs are among the risk factors associated with increased risk of MTCT (WHO 1998), the provision of the routine antenatal package should always be considered part and parcel of a good PMCT program. Resources must be mobilized to ensure continuity of supplies for the basic and essential ANC services of anemia testing, iron and folic acid supplementation, malaria prophylaxis, and syphilis testing and treatment. Iron folate prescriptions should be issued even when supplies are low because women may be able to find an alternative supply source.

\section{Care and support referrals only operate in one direction}

Community links are vital for NDP, both to promote NDP services and to provide follow-up support for mothers after they leave the clinic, yet links with community-based services remain poor. Referrals are still limited to major hospitals for medical reasons only and not to communitybased organizations (CBOs) for social services to meet care and support needs. Increasing collaboration between the clinics and CBOs is required to provide information and ongoing support structures for PLHA. 


\section{References}

Bertolli, J. et al. 1996. "Estimating the timing of mother-to-child transmission of human immunodeficiency virus in a breast-feeding population in Kinshasa, Zaire.” Journal of Infectious Diseases 174(4): 722-6.

de Zoysa, Isabelle et al. 2002. Strategic approaches to preventing HIV infections in infants: balancing priorities in different settings. Abstract ThOrD1431, XIV International AIDS Conferences, Barcelona, Spain, 7-12 July.

Ekpini, E.R. et al. 1997. "Late postnatal mother-to-child transmission of HIV-1 in Abidjan, Cote d'Ivoire." Lancet 349(9058): 1054-9.

Horizons Project. 2000. Assessing the capacity for community-based counseling and referral in the Ndola Demonstration Project. Nairobi: Population Council.

LINKAGES. 1999. Recommended Feeding and Dietary Practices to Improve Infant and Maternal Nutrition. Washington: LINKAGES.

. 2000. World linkages: Zambia country profile. Washington: LINKAGES.

- 2001. "FAQ sheet: frequently asked questions on breastfeeding and HIV/AIDS." Washington: LINKAGES.

Musonda, R.M. et al. 1999. "HIV-1 prevalence using antenatal clinic attenders versus the general population, Ndola, Zambia." Abstract 14ET 3-4, 11 th International Conference on AIDS and STDs in Africa, Lusaka, Zambia, 12-16 September.

NFNC/LINKAGES/SARA/USAID. 1999. "Ndola demonstration project to integrate infant feeding counseling and HIV voluntary testing into health care and community services: HIV and infant feeding." Formative research report. Lusaka: LINKAGES.

UNAIDS/UNICEF/WHO. 1998. HIV and infant feeding: guidelines for decision-makers. UNAIDS/98.3. Geneva: UNAIDS.

White, E. 1999. Breastfeeding and HIV/AIDS: The Research, the Politics, the Women's Responses. Jefferson NC: MacFarland and Company Inc.

WHO Collaborative Study Team on the Role of Breastfeeding on the Prevention of Infant Mortality. 2000. "Effect of breastfeeding on infant and child mortality due to infectious diseases in less developed countries: a pooled analysis." Lancet 355(9202): 451-5. 


\section{${ }^{\mathrm{H}} \boldsymbol{K}^{\text {rizons }}$}

WHO. 2001. "Technical Consultation on Behalf of the UNFPA/UNICEF/WHO/UNAIDS InterAgency Team on Mother-to-Child Transmission of HIV." 11-13 October 2000. Approved 15 January 2001.

Zambia DHS. 1996. Demographic and health survey. Lusaka: Demographic and Health Survey. 


\section{Appendix A}

\section{Service Statistics (J uly 2001)}

Data on service uptake and referrals were collected monthly for the duration of the study, using existing systems already in use at the clinics.

\section{MCH services}

Between January and June 2001, 2,688 women attended as new ANC cases.

Between May 2000 and June 2001 there were 2, 768 deliveries at the health centers. Data were missing for the months of October 2000 and April to May 2001.

Between May 2000 and June 2001, 21,433 women used the family planning services.

Between January and June 2001, 2,734 of the women were new in accepting FP supplies.

The Health Management Information Service does not collect statistics on women receiving a hemoglobin test, malaria prophylaxis, or iron tablets.

\section{Voluntary counseling and testing}

NDP started providing free VCT services in the six DHMT clinics in May $2000 .^{6}$

Between May 2000 and June 2001, 2,132 men and women received VCT services from the six DHMT clinics and Hope Humana.

Between May 2000 and June 2001, 13 percent of all new ANC clients elected to receive VCT.

\section{Infant feeding counseling}

As mentioned earlier, tools tracking the provision of IFC have been under development. Data are not yet available.

\section{Community-based services}

Lubuto clinic's five growth monitoring posts were attended by 1,755 children less than 5 years old, including 467 infants less than 6 months old, during February 2001. Data for the other community sites are not available.

\footnotetext{
${ }^{6}$ Previously, Hope Humana and Ndola Central Hospital had been the only providers of VCT, where services were fee-paying and/or erratic. Free VCT (supported by the MoH) became available at NCH during 1999, and in January 2001 at Hope Humana.
} 


\section{Herizons}

Appendix B

\section{Referrals Data}

By August 2001, the six DHMT clinics had issued 650 referral slips, of which 373 were to Ndola Central Hospital and 275 to the ADH children's hospital. Records have been found for 276 (74 percent) of the NCH referrals and 217 (79 percent) of the ADH referrals, indicating that the patients arrived where they were referred. None of the referrals so far went to CBOs.

The Sisters of the Sacred Heart has used 100 referral slips given by NDP. Of these, 79 could be traced as follows: 52 to the home-based care program of $\mathrm{NCH}, 19$ to Hospice, 2 to ADH, 2 to the $\mathrm{TB}$ clinic at $\mathrm{NCH}$, and 4 to the $\mathrm{NCH}$ casualty department. Hope Humana was provided 50 referral slips in January 2001 and by August 2001 had used 29, 15 traced to NCH, 8 to Zambia Flying Doctors Service, and 1 to the Railway clinic. 


\section{Appendix C}

\section{Ndola Demonstration Project Staff}

\section{Baseline survey (April-June 2000)}

\author{
Interviewers \\ Emmanuel M. Buya \\ Regina M. Bwalya \\ Theresa C. Bwalya \\ Esther K. Cheuka \\ Robert K. Chinyanta \\ Chad Kalobwe \\ Regina Kasompe
}

\author{
Esnelly A. Kasongo \\ Hildah Kaunda \\ Lynette H. S. Maambo \\ Ronah Maambo \\ Queen Moyowanyambe \\ Mary M. Mufaya \\ Joyce Mateo Mulenga \\ Mary Y. Mwamba
}

Poso Ngalande

Esther K. Sakala

Lynn M. Tamba

\section{Secretariat}

Millie Bwalya

Jenipher Ntinda

\section{Nine-month survey (April-June 2001)}

\section{Research Assistants}

Sylvia N. Akapelwa

Veronica Tembo Chilekwa

Mary W. Kaponda

Milner N. Kasempa

Beatrice M. Lupunga

Queen Namukoko Manjimela

Likando Sitali Masinge

Fingani Thomson Mbeba

Queen M. Moyowanyambe

Stephanie B. Mpabalwani

Joyce K. Mwami

Marjory Sydney Mwandu

Mavis M. Mwiinga
Pamela Kalembe Namwanza

Elizabeth M. Nonde

Rhoda Phiri Sakala

Luck A. Silengo

Annie S. Syabeene

Evelyn Chewe Talanki

\section{Supervisors}

Emmanuel Buya

Mary Mwamba

Maureen Mzumara

Tina Nyirenda

Yvonne Shuko
Facilitators

Henry Chiyota

Lynette Maambo

Esther Sakala

Dr Jean Tshiula

\section{Secretariat}

Wendy Dunnett-Dagg

Jenipher Ntinda 


\section{Hgrizons}

Horizons is a global operations research program designed to:

- Identify and test potential strategies to improve HIVIAIDS prevention, care, and support programs and service delivery.

- Disseminate best practices and utilize findings with a view toward scaling up successful interventions.

\section{Population Council}

Horizons is implemented by the

Population Council in collaboration with

- International Center for Research on Women (ICRW)

- International HIVIAIDS Alliance

- Program for Appropriate Technology in Health (PATH)

- Tulane University

- Family Health International (FHI)

- Johns Hopkins University

For more information, please contact:

Horizons Program, Communications Unit 4301 Connecticut Avenue, NW Suite 280 Washington, DC 20008 USA

Tel: 202-237-9400

Fax: 202-237-8410

Email: horizons@pcdc.org www.popcouncil.org/horizons 